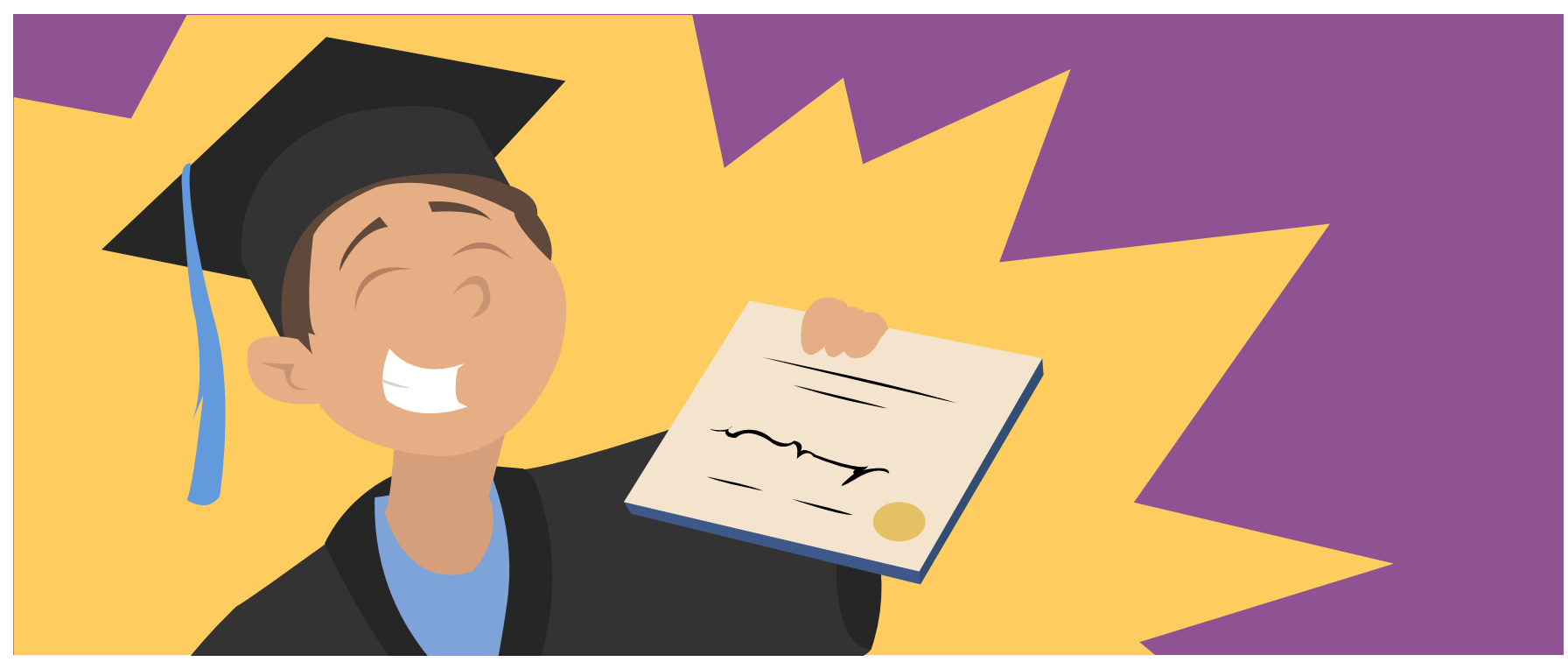

\title{
WHAT IS THE KEY TO SUCCESS? AND HOW DO WE GET THERE?
}

\section{Nellie Kamkar ${ }^{1 *}$, Niki H. Kamkar ${ }^{2}$ and Daniel Ansari ${ }^{2}$}

${ }^{1}$ Department of Applied Psychology and Human Development, The Ontario Institute for Studies in Education (OISE), The University of Toronto, Toronto, ON, Canada, '²epartment of Psychology, University of Western Ontario, London, ON, Canada

\section{REVIEWED BY: \\ EXPLORA SCIENCE CENTER AND CHILDREN'S MUSEUM AGE: 8-14}

If you want to be successful in something, do you simply need to just try harder? Until recently, researchers thought that the key to success is grit, defined as passion and determination to accomplish long-term goals. After studying grit for many years, researchers found that gritty kids are better spellers, gritty teens get better grades, and gritty adults keep their jobs and marriages! Furthermore, there are important brain differences between gritty and less gritty people. So far, you might think the answer to success is grit. More recent research, however, suggests that a personality factor known as conscientiousness is very similar to grit! Conscientiousness is the personality trait of being careful and working hard and we have studied it for a long time.

"Jacob, I don't hear the sound of a piano playing" said Jacob's mother as she looked up the stairs.

"Just five more minutes and I'll get right to it," Jacob exclaimed as he hurriedly put away J.K. Rowling's Harry Potter and the Sorcerer's Stone and dragged his feet to the dusty piano across the hall. 


\section{GRIT}

Perseverance and passion for long-term goals. Grit is similar to a personality trait called conscientiousness. Conscientious people are effortful, careful, vigilant, and they have a need for personal achievement.

\section{FIGURE 1}

Comic strip of Jacob and his mother.
Jacob's mother then began her typical lecture. "You said that 20 minutes ago, Jacob! Enough with the procrastination. You know you'll only get better at something if you practice..."

This series of events had become something of a weekly ritual in Jacob's house and tonight was not different.

As Jacob squinted at the musical notes in front of him, he couldn't help wondering what series of events Harry Potter would find himself in the next chapter.

With each off-key note on the piano, Jacob's mother looked at her son encouragingly, all the while worrying about his piano recital next Tuesday.

Sound familiar? You might be wondering, "Why Jacob (see Figure 1) won't simply try harder and get better at playing the piano?" Or more generally, what makes some people so successful at something, while others lag behind and struggle? Meet Angela Duckworth. Once a school teacher and now a professor and researcher at the University of Pennsylvania, Ms. Duckworth asked the very same question several years ago. The answer may surprise you. In an important set of research studies, she found that a factor that these studies called grit predicts a bunch of successful life outcomes, like getting good grades and graduating [1].

\section{WHAT'S GRIT?}

Grit is defined as dedication and passion for one's long-term goals [1]. Grit is measured by asking people to rate themselves on a scale ranging from 1

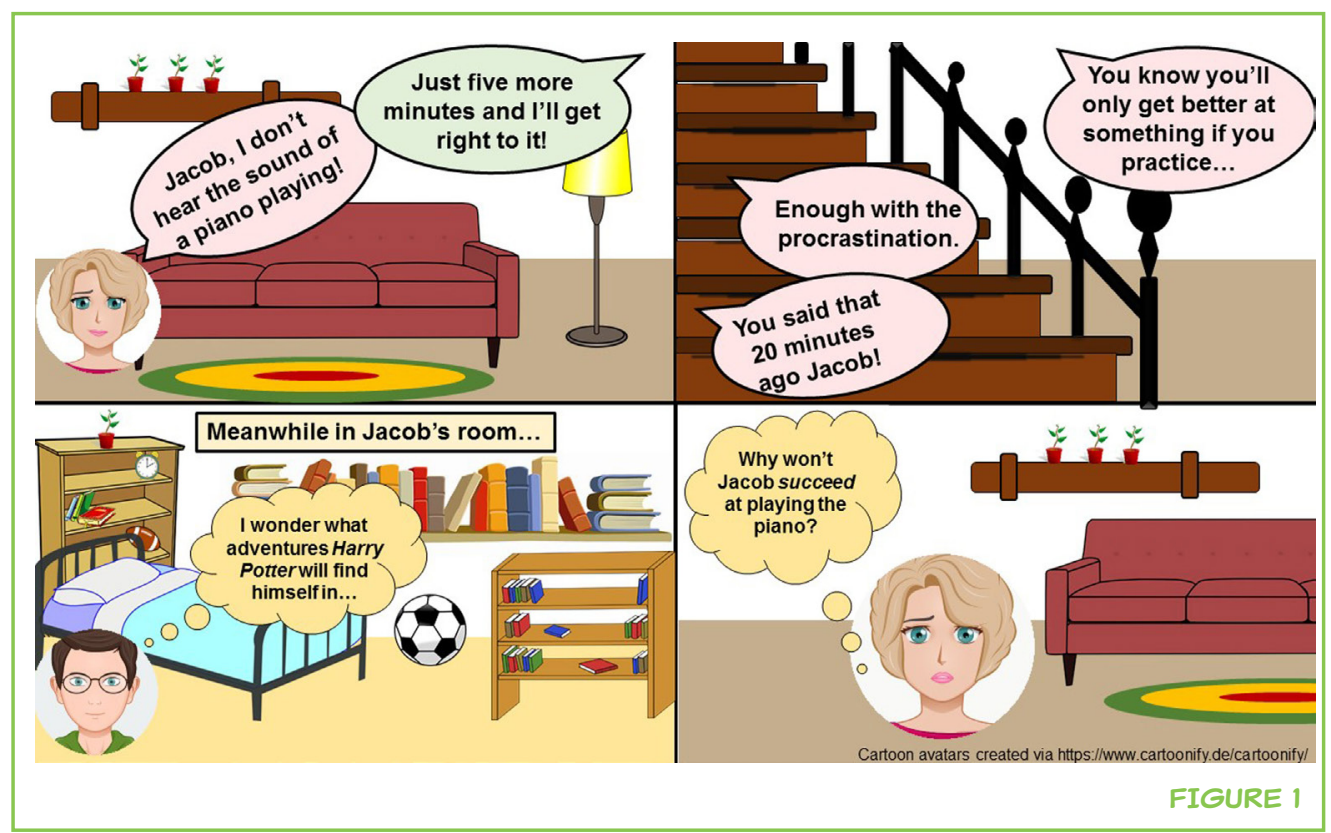


(Not like me at all) to 5 (Very much like me) after reading statements like: "I am a hard worker" and "I am diligent" [1]. The higher one scores on this scale, the "grittier" they are said to be. But why is grit important and what does it have to do with being successful at things?

\section{GRITTY PEOPLE ARE..。}

Better at spelling! In one study, 12-year-old kids who were competing in a national spelling bee were given a series of questionnaires to fill out-including a grit questionnaire. Interestingly, it was not the kids who read books for fun or those who were quizzed on spelling words by their parents who ended up doing better in the spelling bee. Instead, it was the kids who scored high on grit who made it to the final round of the national spelling bee [1]. What's more, gritty high school students are more likely to graduate, and gritty university students get higher grades. In adulthood, gritty employees are more likely to be keeping their jobs and their marriages! [1]. What about the brains of these highly successful, gritty people-what do their brains look like? And furthermore, are the brains of gritty people different from those of not-sogritty, less successful individuals?

\section{GRITTY BRAINS? LET'S TAKE A LOOK AT THE BRAIN SCIENCE BEHIND RESEARCH ON GRIT}

In a recent study, researchers trained 6-year-old kids on a variety of skills to improve their memory. The researchers also measured grit. As I am sure you can probably guess by now, the kids who scored higher on grit had the biggest memory improvements following the training [2]. But are the brains of the gritty 6-year-old different from those of their less gritty peers? This is precisely the question that these researchers asked in the next part of their study. They knew that they needed to see these kids' brains, but how?

\section{NEUROIMAGING}

The process of getting pictures of the structure (shape) of the brain using tools like MRI or, or getting pictures of the function of the brain using $\mathrm{fMRI}$.

\section{VENTRAL}

\section{STRIATUM}

A small region located deep within the brain that is involved in reward processing and motivation.
They used what is called a neuroimaging tool to get pictures of these kids' brains. Neuro means brain and imaging means getting a picture. The specific neuroimaging tool they used is called magnetic resonance imaging (MRI). MRI can be used to look at the shape or structure of the brains. So what did they find? Gritty kids had a differently shaped ventral striatum than did kids who scored lower on grit. What in the world is a ventral striatum? It is a small structure located deep within the core of the brain (colored red in the top part of Figure 2). The ventral striatum is responsible for a bunch of things, some of which include motivation and responding to rewards (like getting a good grade) [2]. So, compared with kids who score low in grit, a part of the brain involved in motivation is shaped differently in super gritty kids. But are these brain differences specific to young kids? What do brain research studies with older kids show?

In a recent study, teenagers completed a grit questionnaire and then they relaxed in a brain scanner [3]. These researchers were not just interested in the shape of people's brains, but instead they wanted to look at the function 


\section{FIGURE 2}

These are brain pictures showing us the two brain areas we have been talking about: the ventral striatum and the prefrontal cortex. The top shows the functioning of the ventral striatum from the back, side, and top of the head. The bottom shows the functioning of the prefrontal cortex from the back, side, and top of the head. These pictures were created by blending together brain pictures of thousands of people from different studies that looked at how these areas function. The reason why we see only one picture for each brain area (instead of thousands) is because all of the pictures were blended together to get an average picture. This way, we can see these parts of the brain functioning in the average person.

\section{PREFRONTAL} CORTEX

A large region located on the surface and front part of the brain that is involved in planning, self-control, and decisionmaking.
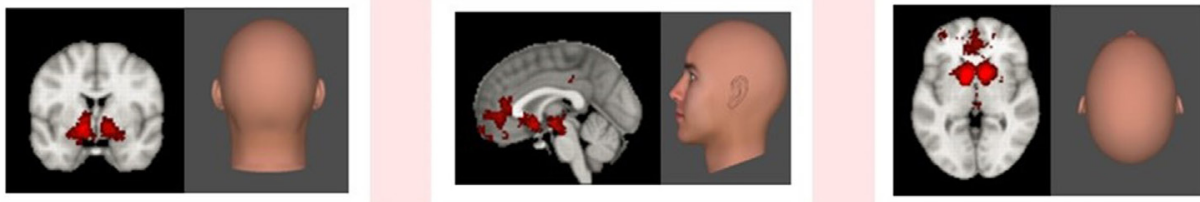

Figure 2 (top).

This figure shows brain activation in the ventral striatum, a part of the brain involved in motivation This part of the brain is shaped differently in gritty kids.

Figure 2 (bottom).

This figure shows brain activation in the prefrontal cortex, a part of the brain involved in self-control. This part of the brain functions differently in gritty teens.
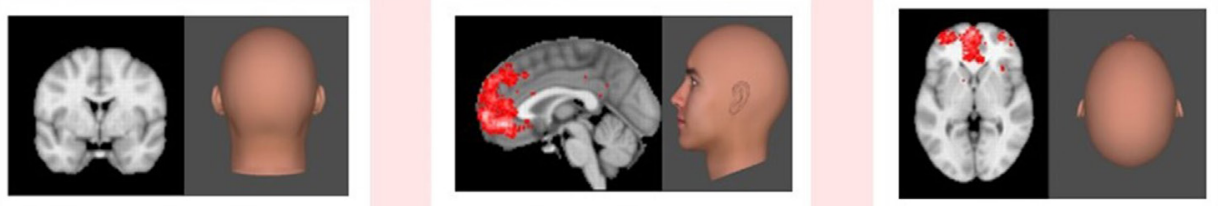

(brain maps retrieved from neurosynth.org, avatars for comparison were generated using FaceGen Modeller 3.13).

FIGURE 2

or activation of their brains. The researchers asked, "Do grittier teens have a different pattern of brain activity when compared with their less gritty counterparts?" After all, the brain is not just a clump of dough sitting in our skulls with nothing to do. We know that the brain is an active organ that communicates with itself and the rest of the body by sending signals to help us think, move, breath, and everything in between. Your brain is sending signals to your eyes telling them to read the words in this article at this very moment! So, these researchers asked the teens in their study to simply relax in a brain scanner used to measure brain activation, a neuroimaging tool called functional magnetic resonance imaging (fMRI). What did they find? Compared with their less gritty peers, grittier teens had a different pattern of brain activity in a part of the brain just behind the forehead - an area called the prefrontal cortex (PFC; bottom of Figure 2). Why is this important? Well, the PFC is involved in functions that are important when we are trying to be successful at a given task; things like planning and self-control [3].

Taking a step back, we can see that grit is linked with two types of brain structures: (1) deep brain structures involved in motivation, like the ventral striatum and (2) brain regions closer to the surface of our faces involved in planning and self-control, such as the PFC. Perhaps, then, gritty people have stronger connections between the deep-rooted brain areas involved in motivation and the more surface-level areas involved in self-control and planning.

\section{BRIDGING THE RESEARCH TOGETHER: CONNECTIONS BETWEEN DEEP AND SURFACE BRAIN AREAS}

One group of researchers wanted to know whether or not grittier kids have deep-rooted motivation brain regions that are activated at the same time as more surface-level brain regions involved in planning and self-control [4]. 
FUNCTIONAL CONNECTIVITY

When two or more brain regions that are far apart become simultaneously activated together. This simultaneous activation suggests that these brain regions work together to accomplish a given task.

Essentially, they wanted to know whether or not the deep and surface brain regions are functionally connected. If both motivation and planning areas of the brain light up at the same time when researchers look using fMRI, then they are said to be functionally connected. Most likely, gritty people are successful because the motivation parts of their brains are connected to the planning parts of their brains. So how did the researchers test this? They used the same tool that we have been discussing so far: fMRI. They studied a sample of preteens who were asked to relax in the scanner and let their minds wander.

They found exactly what you might have guessed: grittier preteens had more functional connectivity (or simultaneous activation) between the ventral striatum and the PFC. So to put it simply, yes, gritty people have simultaneous activation between the motivation parts of their brains and the planning and self-control parts of their brains [4]. In light of all of the evidence presented so far, you might wonder how we can get grittier brains and, as a result, become more successful. How can we become these high-achieving, job-keeping, good grade getting, and amazing spellers? By becoming more gritty right? Well, sort of.

\section{THE OTHER HALF OF THE STORY...}

What we have not told you yet is that, although grit is typically thought of as something that we can teach and learn, there is little actual evidence that people can be trained to have more grit. And furthermore, while it is true that the grit research literature is fascinating, it is not entirely new. In fact, we have known about a personality characteristic that sounds a lot like grit for two decades now: the personality trait of conscientiousness [5]. Conscientiousness is the personality trait of being careful, observant, and hard-working. If you are scratching your head thinking that this sounds a whole lot like grit, you are not alone. Grit and conscientiousness have actually been shown to be very similar [5]. What this suggests is that grit may simply be an old idea (conscientiousness) renamed and branded as something new and original. This shows us that, when we see a concept from psychology being talked about in the media, we should think critically and ask ourselves whether this is actually a new concept, or whether the media is just trying to make it sound that way.

\section{FINAL THOUGHTS...}

Future researchers should ask the following questions: What makes people conscientious? Are people conscientious in every activity that they try? Or, are people conscientious only about the things that they enjoy doing? And importantly, is the true key to success grit itself, or is it figuring out which subjects fascinate us and putting a sincere effort toward those goals? 
Remember our old friend Jacob? He could not wait to read the next chapter of his Harry Potter book and this might be what he should be doing! Reading is what Jacob enjoys, so maybe he could foster and further develop his reading skills. For all we know, Jacob could be a best-selling novelist once he lets his personality guide him toward success.

So what makes people successful and how do we get there? Right now, most of the research suggests that it is our personality that counts. But, we still do not know whether or not putting a sincere effort into tasks and activities that already excite us will make us more successful and change our brains.

\section{REFERENCES}

1. Eskreis-Winkler, L., Shulman, E. P., Beal, S. A., and Duckworth, A. L. 2014. The grit effect: predicting retention in the military, the workplace, school and marriage. Front. Psychol. 5:36. doi:10.3389/fpsyg.2014.00036

2. Nemmi, F., Nymberg, C., Helander, E., and Kingberg, T. 2016. Grit is associated with structure of nucleus accumbens and gains in cognitive training. J. Cogn. Neurosci. 11:1688-99. doi:10.1162/jocn_a_01031

3. Wang, S., Zhou, M., Chen, T., Yang, X., Chen, G., Wang, M., et al. 2016. Grit and the brain: spontaneous activity of the dorsomedial prefrontal cortex mediates the relationship between the trait grit and academic performance. Soc. Cogn. Affect. Neurosci. 12(3):452-60. doi:10.1093/scan/nsw145

4. Myers, C. A., Wang, C., Black, J. M., Bugescu, N., and Hoeft, F. 2016. The matter of motivation: striatal resting-state connectivity is dissociable between grit and growth mindset. Soc. Cogn. Affect. Neurosci. 11(10):1521-7. do::10.1093/scan/ nsw065

5. Credé, M., Tynan, M. C., and Harms, P. D. 2016. Much ado about grit: a metaanalytic synthesis of the grit literature. J. Pers. Soc. Psychol. 113(3):492-511. doi:10.1037/pspp0000102

SUBMITTED: 16 July 2017; ACCEPTED: 28 February 2018; PUBLISHED ONLINE: 20 March 2018.

EDITED BY: Kathleen Haaland, University of New Mexico, United States

CITATION: Kamkar N, Kamkar NH and Ansari D (2018) What is the Key to Success? And How Do We Get There? Front. Young Minds 6:12. doi:10.3389/frym.2018.00012

CONFLICT OF INTEREST STATEMENT: The authors declare that the research was conducted in the absence of any commercial or financial relationships that could be construed as a potential conflict of interest.

COPYRIGHT (C 2018 Kamkar, Kamkar and Ansari. This is an open-access article distributed under the terms of the Creative Commons Attribution License (CC BY). The use, distribution or reproduction in other forums is permitted, provided the original author(s) and the copyright 


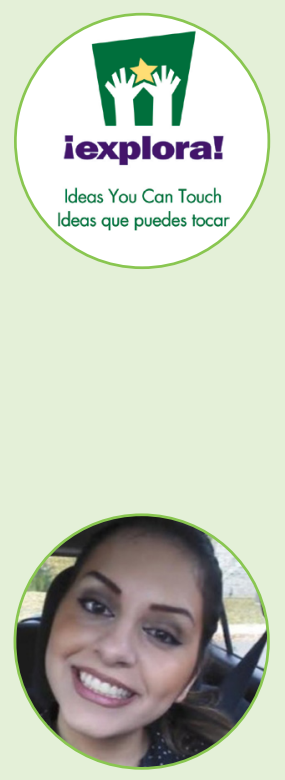

owner are credited and that the original publication in this journal is cited, in accordance with accepted academic practice. No use, distribution or reproduction is permitted which does not comply with these terms.

\section{REVIEWED BY}

\section{EXPLORA SCIENCE CENTER AND CHILDREN'S MUSEUM, AGE: 8-14}

The Explora Young Minds reviewers are a group of science enthusiasts working with museum educators and mentors from the University of New Mexico. We enjoy learning about the brain through the articles and hands-on activities and demonstrations. We also enjoy reading about new research, asking questions, and making suggestions to help the scientists make their work more understandable for everyone!

\section{AUTHORS}

\section{NELLIE KAMKAR}

I recently completed my Master's degree in developmental psychology at The University of Western Ontario. For my Master's, I studied how preschoolers learn from social information. Next year, I will be pursuing my Ph.D. at The University of Toronto with a focus on educational psychology. For my Ph.D., part of my work will examine what factors make some kids successful in school and others not. During my free time, I enjoy painting, watching movies, and writing poems. *nellie.kamkar@mail.utoronto.ca

\section{NIKI H. KAMKAR}

I am a Ph.D. student at the University of Western Ontario in developmental psychology. I am also a part-time professor at Fanshawe College. My research focuses on how early life experiences shape the brain's reward and motivational systems. I want to determine whether children who experience a lot of life stress learn differently from rewards (like getting a good grade or a smiley face on a test) versus losses (like getting a bad grade or a red "X" on a test). My hobbies, include both reading and writing fiction and eating ice-cream.

\section{DANIEL ANSARI}

I am interested in how our brains process numbers and how we use them. We use numbers all the time. I want to know how the human brain is able to know about numbers and why some children find numbers so hard to understand. What is different about their brains? Why do some people find numbers really scary while others love to use them? 